\title{
Yeast rRNA Expansion Segments: Folding and Function
}

Lizzette M. Gómez Ramos ${ }^{1,2}$, Johanna M. Smeekens ${ }^{1}$, Nicholas A. Kovacs ${ }^{1}$, Jessica C. Bowman ${ }^{1}$, Roger M. Wartell ${ }^{3}$, Ronghu $\mathrm{Wu}^{1}$ and Loren Dean Williams ${ }^{1 *}$

1. School of Chemistry and Biochemistry, 2. School of Chemical and Biomolecular Engineering, 3. School of Biology

Georgia Institute of Technology, 315 Ferst Drive NW, Atlanta, GA 30332-0363, USA.

*Email: loren.williams@chemistry.gatech.edu

Phone: 404-894-9752, Fax: 404-894-7452

Keywords: aminoacyl tRNA synthetases/rRNA expansion segments/rRNA-protein interaction/SHAPE/thermal unfolding

Abbreviations: aminoacyl tRNA synthetase - aaRS, dissociation constant - $K_{d}$, expansion segment ES, Large ribosomal subunit - LSU, Ribosomal RNA - rRNA, transfer RNA - tRNA

(C) 2016. This manuscript version is made available under the Elsevier user license http://www.elsevier.com/open-access/userlicense/1.0/ 


\begin{abstract}
Divergence between prokaryotic and eukaryotic ribosomal RNA and among eukaryotic ribosomal RNAs is focused in Expansion Segments (ESs). Eukaryotic ribosomes are significantly larger than prokaryotic ribosomes in part because of their ESs. We hypothesize that larger rRNAs of complex organisms could confer increased functionality to the ribosome. Here we characterize binding partners of $S$. cerevisiae expansion segment 7 (ES7), which is the largest and most variable ES of the eukaryotic large ribosomal subunit and is located at the surface of the ribosome. In vitro RNA-protein pull-down experiments using ES7 as a bait indicate that ES7 is a binding hub for a variety of non-ribosomal proteins essential to ribosomal function in eukaryotes. ES7-associated proteins observed here cluster into four groups based on biological process, (i) response to abiotic stimulus (e.g. response to external changes in temperature, $\mathrm{pH}$, oxygen level, etc.), (ii) ribosomal large subunit biogenesis, (iii) protein transport and localization, and (iv) transcription elongation. Seven synthetases, Ala-, Arg-, Asp-, Asn-, Leu-, Lys- and Tyr-RS appear to associate with ES7. Affinities of AspRS, TyrRS and LysRS for ES7 were confirmed by in vitro binding assays. The results suggest that ES7 in S. cerevisiae could play a role analogous to the multi-synthetase complex present in higher order organisms and could be important for the appropriate function of the ribosome. Thermal denaturation studies and footprinting experiments confirm that isolated ES7 is stable and maintains a near-native secondary and tertiary structure.
\end{abstract}




\section{INTRODUCTION}

The core function of the ribosome is to read mRNA and synthesize coded protein. In addition, ribosomes facilitate protein folding, protein degradation, stress response and mRNA surveillance [1-3]. The increased size of rRNAs in complex organisms appears to confer increased functionality to the ribosome [4]. Many auxiliary functions of large ribosomes are yet to be characterized. However, auxiliary functions correlate with rRNA size, which follows well-defined patterns.

(i) All cytoplasmic ribosomes contain a "common core" of rRNA, which is reasonably approximated in structure by prokaryotic rRNA (Figure 1).

(ii) Expansion of rRNA beyond the common core is focused in a few specific regions on the ribosome called "expansion segments" (ESs) [5-9].

(iii) ESs are located on the surface of the ribosome and are excluded from the ribosome interior and from core functional centers such as the PTC, the decoding center, the subunit interface, and tRNA binding sites [10].

(iv) Size variation is significantly greater in eukaryotes than prokaryotes and in large subunit (LSU) rRNAs than in small subunit (SSU) rRNAs [8].

(v) rRNA size increases from bacteria/archaea to protists to metazoan and is greatest in mammals $[4,9]$.

(vi) rRNA size correlates with organismal complexity [4].

Insert Figure 1 here.

Here we investigate the functions of Expansion Segment 7 (ES7, Figure 1) of Saccharomyces cerevisiae. ES7 is an extension of Helix 25 of the prokaryotic ribosome and is among the largest expansion segments of the LSU and the ribosome as a whole. ES7 is one of the most variable regions of eukaryotic rRNA. It is 210 nucleotides (nts) in S. cerevisiae (Figure 2), 341 nts in Drosophila melanogaster, $800 \mathrm{nts}$ in Gallus gallus and $876 \mathrm{nts}$ in Homo sapiens. The locations of ESs on the surface of the ribosome were established by Dervan and coworkers [11] and confirmed by threedimensional structure determination [reviewed in reference 9].

The ribosome has grown in size and complexity within certain branches of the eukaryotic tree. The LSU rRNA of $S$. cerevisiae is $3554 \mathrm{nts}$, while that of D. melanogaster is $4078 \mathrm{nts}$, G. gallus is $4725 \mathrm{nts}$ and $H$. sapiens is $5227 \mathrm{nts}$. It has been proposed that ESs are involved in ribosomal regulation, packaging, turnover and biogenesis [12-14]. In trypanosomes, ESs of the small 
ribosomal subunit contribute to a 'turret-like' structure, linking the small and large subunits [15]. The location of the turret suggests a role in translation initiation [16].

Insert Figure 2 here.

We characterize the secondary structure and protein binding capabilities of ES7. The results are consistent with a model in which expansion segments of eukaryotic ribosomes are docking sites for protein factors that are auxiliary to core ribosomal functions. These factors include aminoacyl tRNA synthetases (aaRSs), quality control proteins and chaperones.

\section{RESULTS}

\section{Protein Binding to S. cerevisiae ES7}

S. cerevisiae cell lysates were screened for proteins with affinity for ES7 using pull-down assays. Mass spectrometry (MS) was used to identify ES7-associated proteins extracted from the lysates. Thirty-six proteins (Table S.6) were seen to interact with ES7 during exponential growth of S. cerevisiae. Our assay identifies primary proteins that interact directly with ES7 in addition to secondary proteins that bind to the primary proteins.

As an illustration of the process used here for identifying ES7-associated proteins, a tandem mass spectrum corresponding to a peptide from lysyl-tRNA synthetase is shown in Figure S.1. We attached isolated ES7 to beads, incubated the beads with cell lysates, washed the beads to remove non-specific and weakly associated proteins, and then proteolytically digested the ES7-associated proteins. The peptide ELELNFSRPWK was identified with an XCorr of 3.0, and a mass accuracy of $0.69 \mathrm{ppm}$. XCorr values represent the correlation between tandem mass spectra recorded in our experiment and the corresponding theoretic spectra of peptides in the database. The higher the XCorr, the greater the confidence in peptide identification. Similarly, mass accuracies determine the extent to which theoretical masses match observed masses of peptides in our experiments. Mass accuracies of less than $3 \mathrm{ppm}$ indicate high confidence in peptide identification.

Many of the proteins seen here to associate with ES7 have been shown previously to bind to the ribosome. Twenty five of the thirty six ES7-associated proteins here were identified by Link as components of intact translation complexes [17]. These proteins include Aspartyl tRNA synthetase (AspRS), Translation Machinery-Associated Protein 10 (TMA10), Ribosome biogenesis protein ERB1 and ATP-dependent RNA helicase MAK5. Twelve of them were identified as mRNA-binding proteins (mRBPs) by Hentze [18]. Nine proteins that associate with ES7 in this work were found 
previously to associate with both intact ribosomes and with mRNA $[17,18]$. Those nine are (i) protein transport factor SEC1, (ii) MAK21, which is involved in maturation and export of pre-LSU particles, (iii) fimbrin, actin-bundling protein involved in cytoskeleton organization and maintenance, (iv) HXK1, which catalyzes hexose phosphorylation, (v) NAD(+) salvage pathway component, nicotinamidase, (vi) transcription elongation factor SPT6, (vii) AspRS, (viii) 40S ribosomal protein S30, and (iv) protein PBI2, inhibitor of vacuolar protein B.

Seven aminoacyl tRNA synthetases (aaRSs) were identified here in association with ES7. AspRS and TyrRS were found in each of the replicate experiments. Cumulatively Ala-, Arg-, Asn-, Asp-, Leu-, Lys- and Tyr-RS were observed in at least one experiment. Our observations are consistent with Link et al., [17] who observed Ala-, Asn-, Asp-, Leu- and Lys-RS bound to intact ribosomes. Asp-, Leu- and Lys-RS associate more tightly with the intact ribosome than AlaRS and AsnRS. The binding of AspRS, TyrRS and LysRS to ES7 is confirmed here by in vitro binding assays (below).

A total of six proteins known to localize in the nucleolus [19] are observed here to associate with ES7. Nucleolar proteins that associate with ES7 include (i) MAK5, (ii) MAK21, (iii) ERB1, (iv) Ribosome biogenesis ATPase RIX7, (v) DNA-directed RNA polymerase I subunit RPA49 and (vi) RNA 3'-terminal phosphate cyclase-like protein RCL1.

Clustering of ES7-associated proteins by biological process was performed using the Database for Annotation, Visualization and Integrated Discovery (DAVID) [20, 21]. Four clusters are highly enriched (Figure 3), including (i) response to abiotic stimulus such as temperature, (ii) ribosomal large subunit biogenesis, (iii) protein transport and localization, and (iv) transcription elongation. For this analysis, if multiple clusters contained identical proteins, only the cluster with the lowest $P$-value was retained. The two most intense clusters correspond to response to abiotic stimulus $\left(P=5.3 \times 10^{-3}\right)$ and ribosomal LSU biogenesis $\left(P=1.03 \times 10^{-2}\right)$. Clusters with $P$ values lower than 0.05 are considered to be highly enriched and thus specifically associated with the corresponding biological process. With DAVID we were unable to cluster all thirty six ES7associated proteins because the functional annotation for the S. cerevisiae proteome is not fully finalized in the database. Twelve of the thirty six ES7-associated proteins were not clustered. Six mitochondrial proteins observed were assumed to be artifacts and were excluded from the analysis.

For comparison, we clustered Hentze's mRBPs by the same methods we used here for ES7associated proteins, and observed some of the same clusters. Clusters common to mRBPs and ES7associated proteins include (i) response to abiotic stimulus and (ii) protein transport and localization. ES7-associated proteins were also clustered based on molecular function with DAVID 
(Figure 3). The results demonstrate that ES7-associated proteins are important in (i) nucleotide binding and (ii) catalytic activity. Both of these clusters are also seen in mRBPs.

Insert Figure 3 here.

\section{S. cerevisiae ES7 Forming Complexes with tRNA Synthetases in vitro}

To assess the validity of the results of the pull-down experiments, and to determine if some of the associations are direct or are mediated by other proteins, we selected three ES7-associated proteins and assayed their affinities for ES7 in vitro. The affinities of Asp-, Lys- and Tyr-RS for ES7 were assayed by Electrophoretic Mobility Shift Assay (EMSA). The results (Figure 4) demonstrate that Asp-, Lys- and Tyr-tRNA synthetases bind tightly to ES7, and suggest that the interaction we detect is direct and is not mediated by other proteins. One $\mu \mathrm{M}$ of rRNA and $1 \mu \mathrm{M}$ of protein produce a single shifted rRNA band. It is probable that aaRS proteins bind to ES7 rRNA with 1:1 stoichiometry. Control experiments show that the affinities for ES7 rRNA are 3x to 10x greater than for a different fragment of rRNA (Figure S.2).

Insert Figure 4 here.

For these 1:1 complexes, gels were quantitated and dissociation constants, $K_{d}$ 's, were estimated to be approximately $100 \mathrm{nM}$ for Lys-tRNA synthetase and $1 \mathrm{uM}$ for Asp- and Tyr-tRNA synthetases. The affinities of these aaRS proteins for ES7 are roughly equivalent to the affinities observed elsewhere for ribosomal proteins for cognate rRNA [22, 23]. $K_{d}$ 's in the low micromolar to nanomolar ranges have been observed for ribosomal proteins uL1, uL2, uL3 and uL6 with rRNA.

Multi-protein EMSA experiments do not provide evidence of simultaneous binding of multiple aaRSs to ES7 (Figure 4D, Figure S.3). Lys- and Tyr-RS were selected for this assay based on the differential migration of the free proteins in native-PAGE. A fixed amount of ES7 RNA was incubated with TyrRS, LysRS and a combination of TyrRS and LysRS. The mobilities of LysRS and TyrRS alone differ from the mobility of the ES7-LysRS and ES7-TyrRS complexes. Incubation of ES7 simultaneously with TyrRS and LysRS showed at least two distinct bands that correspond to ES7LysRS and ES7-TyrRS complexes. Bands suggesting the formation of additional ES-aaRS complexes could not be observed. The data does not support formation of the ES7-LysRS-TyrRS complex.

Secondary Structure of ES7 
SHAPE footprinting [24, 25], computational folding [26] and phylogenetic data were used to determine the secondary structure of isolated $S$. cerevisiae ES7, which is seen to be the same as the ES7 secondary structure in the Yusupov three-dimensional structure [27] and the secondary structure of purified ribosomes determined by Dinman [28]. SHAPE monitors relative reactivity of

2'-oxygens to an electrophile, indicating extent of local flexibility. Nucleotides in unpaired loops and bulges and in non-canonical base pairs show elevated SHAPE reactivity while canonical helical regions show depressed SHAPE reactivity. A direct comparison of the SHAPE reactivity of isolated ES7 to that of Dinman's ES7 secondary structure demonstrates that the secondary structure of isolated ES7 in vitro is the same as in intact ribosomes.

SHAPE reactivities were determined for all nucleotides of isolated S. cerevisiae ES7 (Figure 5A). Nucleotides were clustered into three groups based on their SHAPE reactivity, after background subtraction and normalization. Positions of low SHAPE reactivity $(<0.4)$ are located in helical regions in the secondary structure, whereas moderate and highly reactive SHAPE positions ( $>0.4)$ are concentrated in bulges, loops and RNA mismatches. The observed SHAPE data is fully consistent with the secondary model shown.

Insert Figure 5 here.

\section{Tertiary Structure}

Changes in SHAPE reactivity suggest that $\mathrm{Mg}^{2+}$ induces formation of tertiary interactions in isolated ES7. Previously, the $\mathrm{Mg}^{2+}$ dependence of SHAPE reactivity was determined for a variety of RNAs including tRNA [29], RNase P [30], Domain III [31] and the intact LSU rRNA of Thermus thermophilus (Timothy K. Lenz, Nicholas Hud and Loren Williams, unpublished observations). The data were interpreted to indicate formation of tertiary interactions upon addition of $\mathrm{Mg}^{2+}$. We have used this comparative method to demonstrate specific inter-domain, intra-domain and subunit folding of LSU rRNA caused by addition of $\mathrm{Mg}^{2+}[31,32]$.

SHAPE data obtained in the presence of $\mathrm{Na}^{+}$alone (Figure $5 \mathrm{~A}$ ) was subtracted from that obtained in the presence of $\mathrm{Na}^{+}$and $\mathrm{Mg}^{2+}$ (Figure $5 \mathrm{~B}$ ). The heat map obtained by this method (Figure 5C) identifies nucleotides that increase or decrease in reactivity upon addition of $\mathrm{Mg}^{2+}$. It can be seen that canonical helical regions are invariant to the addition of $\mathrm{Mg}^{2+}$, consistent with the expectation that secondary structure is maintained upon formation of tertiary structure. Changes in reactivity are focused on loops and non-helical regions, which are expected to be involved in 
tertiary interactions. The results suggest that isolated ES7 of $S$. cerevisiae forms tertiary interactions upon addition of $\mathrm{Mg}^{2+}$.

\section{Thermal Folding/Unfolding of S. cerevisiae ES7}

Isolated ES7 is well-behaved in solution. The number of transitions in the unfolding process provides information on the architecture of ES7. Thermal melts show that the folded structure is stable at room temperature and that folding and unfolding are reversible. Thermodynamic parameters were obtained from the melting curves by non-linear fitting to a multi-state model with independent transitions (Figure S.4) [33]. An estimate of the number of melting transitions and the thermodynamic parameters associated with these transitions is obtained from the melting profile, which is the derivative of the fraction unfolded $(\mathrm{d} \theta / \mathrm{dT})$ as a function of temperature (Figure 6). The best fit to the melting profile of ES7 was obtained with a four transition model (Figure 6). A three-transition unfolding model gives significantly worse statistics of fit. However, unfolding models with additional transitions cannot be excluded by the methods used here and in fact are probable for such a large RNA.

Melting profiles were fit and de-convoluted to obtain estimates of thermodynamic parameters for each of the four transitions. The melting temperatures $\left(\mathrm{T}_{\mathrm{m}, \mathrm{n}}\right)$ of the transitions are $\mathrm{T}_{\mathrm{m}, 1}=51^{\circ} \mathrm{C}, \mathrm{T}_{\mathrm{m}, 2}=64^{\circ} \mathrm{C}, \mathrm{T}_{\mathrm{m}, 3}=75^{\circ} \mathrm{C}$ and $\mathrm{T}_{\mathrm{m}, 4}=83^{\circ} \mathrm{C}$ in $180 \mathrm{mM} \mathrm{NaCl}$. The highest temperature transition has a relatively small hyperchromicity but was retained in the model because it is reproducible and is observed in the thermal melting of isolated ES7 rRNA from a closely related fungi (unpublished observations). In this method, uncertainty arises because enthalpies can correlate with hyperchromicities [33]. The $\mathrm{T}_{\mathrm{m}}$ 's are constant with varying RNA concentrations (unpublished observations) indicating that the transitions are unimolecular. Since ES7 rRNA is large and is subject to degradation, $\mathrm{Mg}^{2+}$ was excluded from melting buffers to prevent in-line cleavage [34]. Additional information on thermodynamic models and parameter estimation are provided in Supplementary Materials.

Insert Figure 6 here.

\section{DISCUSSION}

Mammals have the largest known rRNAs. Metazoans have larger rRNAs than protists, which have larger rRNAs that prokaryotes. We suggest that breadth of ribosomal function is related to the size of the rRNA [4] and that eukaryotic ribosomes facilitate functions that are auxiliary to 
translation. One of the foci of rRNA expansion is ES7. By determining which proteins associate with ES7 we can deduce at least some of its contributions to function.

At least 36 proteins in cell lysates bind here to isolated ES7 rRNA of S. cerevisiae directly or through intermediates. Twenty five of these ES7-associated proteins were previously identified by Link in association with intact ribosomes [17]. It appears we have identified the subset of Link's proteins that bind to ES7 rRNA as opposed to other regions of the ribosome. Twelve of the ES7associated proteins observed here were also identified as mRNA-binding proteins (mRBPs) by Hentze [18]. Some proteins identified here may bind at multiple sites on the ribosome. Six of the ES7-associated proteins reside in the nucleolus consistent with roles of ES7 in ribosome biogenesis [35].

ES7-associated proteins were clustered with DAVID [21,36] into four groups based on biological process, (i) response to abiotic stimulus such as temperature, (ii) large subunit ribosomal biogenesis, (iii) protein transport and localization, and (iv) transcription elongation (Figure 3). Clustering based on molecular function shows ES7-associated proteins are important in nucleotide binding and catalytic activity.

aaRSs. aaRSs couple amino acids with their cognate tRNAs, establishing the relationship of nucleotide triplets with amino acids (i.e., the genetic code). Cumulatively seven synthetases, Ala-, Arg-, Asp-, Asn-, Leu-, Lys- and Tyr-RS were observed in at least one experiment. ES7 may be a focus of aaRS association on the ribosome. Previously, sixteen aaRSs were observed to associate with intact ribosomes in S. cerevisiae [17]. ES7 may be an ancestor or proxy of large multi-aaRS complexes in other systems, maintaining close association of synthetases with each other and with the translational machinery. In S. cerevisiae, only two aaRSs are found in multi-synthetase complex [37]. These two aaRSs are not observed here to associate with ES7. Half of the ES7-assocated aaRSs in S. cerevisiae correspond with those observed previously in the human multi-aaRS complex [38]. Yeast two-hybrid studies in archaea suggest that EF-1 $\alpha$ associates with LeuRS and contributes to the overall translation efficiency by promoting aminoacylation [39]. Our work complements these findings. ES7 could act as a hub for tRNA aminoacylation and for improving translation efficiency.

Affinity and specificity of AspRS, TyrRS and LysRS for ES7 were confirmed by in vitro binding assays. AspRS and TyrRS were observed in each of the replica experiments and appear to be the most robust ES7 binders. The affinities and specificities of Asp-, Lys- and Tyr-RS's for ES7 were assayed by EMSA. The data suggest that these aaRS proteins bind to ES7 rRNA with 1:1 stoichiometry. Their affinities for ES7 are greater than for a different rRNA fragment (Figure S.2). 
The results also suggest that these three aaRSs bind directly to ES7 supporting the hypothesis that ES7 in S. cerevisiae might promote close association of aaRSs with each other and with the ribosome. Based on the direct association of ES7 to Asp-, Lys- and Tyr-aaRSs it seems likely that additional aaRSs might bind to ES7 in vivo and may form stable RNA-protein complexes. Multiprotein EMSA does not provide evidence for simultaneous association of ES7 with multiple aaRSs.

Observations of RNA - protein association in pull down experiments must account for specificity. A complex observed experimentally might not be relevant in vivo because of competition from other factors. Several measures were taken to control non-specific RNA-protein binding. For a subset of the ES7-associated proteins we have directly confirmed high affinities in vitro (Figures 4, S.2 and S.3). ES7 has 26,000 $\AA^{2}$ of accessible surface area when stripped of ribosomal proteins and $20,000 \AA^{2}$ of accessible surface area in the assembled ribosome. Therefore ES7 provides ample surface area for association with non-ribosomal proteins. Considering that rRNA accounts for over $80 \%$ of cellular RNA [40], competition from other RNAs seems unlikely, and the proteins detected here must be considered highly probable ES7 binding partners in vivo. However, binding of proteins could be transient and might depend upon the stage cell cycle and on external cell environment. We expect that the majority of the proteins identified in this study are representative of the proteins that bind to ES7 in vivo during log phase, although we cannot exclude additional binding partners.

Ribosomal Proteins. Although some nucleolar proteins were identified, it seems likely that nucleoli and intact nuclei were depleted prior to the assay. None of the ES7-associated proteins found here are ribosomal proteins. ES7 rRNA does contact multiple ribosomal proteins in the assembled ribosome (Figure 2). rProtein uL4 makes the most extensive contacts with ES7, yet is not observed in our assay. It is possible that uL4 in the cytoplasm is tied up in association with ribosomes, and that the amount of free uL4, not associated with assembled LSU's, is sufficiently small that it cannot be detected in our assay.

ES7 Folding. Our footprinting and folding/unfolding experiments along with computational studies indicate that isolated ES7 folds to a native-like secondary structure, consistent with the secondary structure inferred for intact $S$. cerevisiae ribosomes $[27,28]$. In the presence of $\mathrm{Mg}^{2+}$, isolated ES7 forms tertiary interactions. The thermal melting shows that folded ES7 is highly stable and that the multistate folding/unfolding process is reversible. Combined, the results provide experimental confirmation of the secondary structure of $S$. cerevisiae ES7, and suggest our experiments employed a native-like structure of ES7 rRNA. 
Conclusions. We hypothesize that expansion segments could be sites of functional interactions with other macromolecules given their proximity to the ribosome surface. ES7 is the largest expansion segment and the most variable region of rRNA over phylogeny. We performed in vitro characterization of $S$. cerevisiae ES7 by measuring its stability, and its interactions with cellular proteins. The results here support our hypothesis. Here, we demonstrate that Asp-, Lysand Tyr- tRNA synthetases bind directly to S. cerevisiae ES7. aaRSs charge amino acids with their cognate tRNAs catalyzing the first reaction needed for protein synthesis [41]. Therefore, expansion segments likely play a variety of important roles in protein synthesis.

\section{MATERIALS AND METHODS}

\section{S. cerevisiae ES7 DNA and RNA}

The DNA encoding S. cerevisiae ES7 was amplified from yeast genomic DNA. The T7 promoter and restriction sites for EcoRI (5' end) and HindIII (3' end) were added via PCR. The DNA was inserted into a previously restricted, dephosphorylated pUC19 plasmid. Ligated plasmid was transformed into DH5 $\alpha$ competent cells and colonies were selected based on X-gal Blue-White screening (Thermo Scientific). Primer sequences are shown in Table S.1.

The Weeks cassette [42] was incorporated onto the 3' end of ES7 to allow SHAPE mapping without losing information from ES7 termini using the Q5® Site-directed Mutagenesis Kit (New England BioLabs). Primer information is described in Table S.2. Primer synthesis and DNA sequencing were performed by Eurofins-MWG Operon.

In vitro RNA Synthesis

S. cerevisiae ES7 RNAs were transcribed (HiScribe ${ }^{\mathrm{TM}}$ T7 High Yield RNA Synthesis Kit, New England BioLabs) with the following modifications to the manufacturer's protocol. pUC19 containing the $S$. cerevisiae ES7 gene was linearized at the 3' end with HindIII. Five hundred ng of DNA template were used in each $20 \mu \mathrm{L}$ transcription reaction. The DNA was transcribed overnight at $37^{\circ} \mathrm{C}$ followed by incubation with TURBO DNase (Ambion) at $37^{\circ} \mathrm{C}$ for $15 \mathrm{~min}$. Ammonium acetate (1:10 dilution, $5 \mathrm{M} \mathrm{pH} \mathrm{5.6)} \mathrm{and} \mathrm{100 \%} \mathrm{ethanol} \mathrm{(2.5} \mathrm{vol.)} \mathrm{were} \mathrm{added} \mathrm{to} \mathrm{the} \mathrm{reaction} \mathrm{mixture,}$ which was then incubated at $-20^{\circ} \mathrm{C}$ for $1 \mathrm{~h}$ and centrifuged at $15,600 \mathrm{xg}$ at $4{ }^{\circ} \mathrm{C}$ for $10 \mathrm{~min}$. Pellets were washed three times with $80 \%$ ethanol before drying via Speedvac. RNA was re-suspended in nuclease-free water and then purified from un-incorporated nucleotides with an ilustra NAP 5 column (GE Healthcare). RNA yields were quantified by UV absorbance. RNA purity and integrity were verified by $6 \%$ acrylamide, $8 \mathrm{M}$ urea gel with TBE buffer. 


\section{SHAPE Reactions}

Selective 2'-Hydroxyl Acylation Analyzed by Primer Extension (SHAPE) methods were adapted from published protocols $[32,42]$. In vitro-transcribed RNA in nuclease-free water was added to folding buffer (final concentrations: $200 \mathrm{mM} \mathrm{NaOAc}, 50 \mathrm{mM}$ NaHEPES pH 8.0 and $1 \mathrm{mM}$ 1,2-cyclohexanediaminetetraacetic acid or $5 \mathrm{mM}$ of $\mathrm{MgCl}_{2}$ ) to obtain $400 \mathrm{nM}$ RNA in $80 \mu \mathrm{L}$. RNAs were annealed by cooling from $75^{\circ} \mathrm{C}$ to $25^{\circ} \mathrm{C}$ at $1{ }^{\circ} \mathrm{C} / \mathrm{min}$. Data were collected in $200 \mathrm{mM} \mathrm{Na}^{+}$and no magnesium to analyze secondary structure [43-45]. RNA tertiary interactions were characterized in the presence of $\mathrm{Mg}^{2+}$ ions.

\section{Benzoyl Cyanide Reaction}

Chemical modification of ES7 RNA was performed with a 10x dilution of a $1000 \mathrm{mM}$ benzoyl cyanide (Sigma) stock prepared in DMSO into $36 \mu \mathrm{L}$ of annealed RNA. Control reactions contained DMSO only. Reactions were carried out for 1-2 min at room temperature [30].

Benzoyl cyanide-modified RNA was purified from reaction mixtures by precipitation in ammonium acetate (1:10 dilution, $3 \mathrm{M} \mathrm{pH} 5.2)$ and ethanol $(2.5 \mathrm{vol})$ at $-20^{\circ} \mathrm{C}$ for $\sim 15 \mathrm{~min}$. Reaction mixtures were centrifuged at $15,600 \mathrm{xg}$ at $4^{\circ} \mathrm{C}$ for $10 \mathrm{~min}$ and the pellet washed once with $80 \%$ ethanol before drying via Speedvac. Pellets were re-suspended in $22 \mu \mathrm{L} 1 \mathrm{x}$ TE buffer (10 mM Tris$\mathrm{Cl}, 1 \mathrm{mM}$ EDTA, pH 8.0). Recovery after purification was $>40 \%$.

\section{Reverse Transcription of Benzoyl Cyanide-modified S. cerevisiae ES7 RNA}

A single [6-FAM]-labeled primer (Table S.3) provided complete SHAPE reads on ES7 of $S$. cerevisiae [29]. Modified RNA (20 $\mu \mathrm{L})$ was added to 40 pmol primer in reverse transcription (RT) buffer to yield 1X First-Strand Buffer (Invitrogen), 2 mM DTT and $625 \mu \mathrm{M}$ of each deoxynucleotidetriphosphate (dNTP) in $50 \mu \mathrm{L}$. Primer annealing was performed stepwise: $95^{\circ} \mathrm{C}$ for $30 \mathrm{sec}, 65^{\circ} \mathrm{C}$ for $3 \mathrm{~min}, 60^{\circ} \mathrm{C}$ for $3 \mathrm{~min}$ and $4{ }^{\circ} \mathrm{C}$ for $10 \mathrm{~min}$. SuperScript III Reverse Transcriptase (Invitrogen) was used in RT reactions. RT mixtures were pre-incubated at $52{ }^{\circ} \mathrm{C}$ for 2 min before addition of $1 \mu \mathrm{L}(200 \mathrm{U})$ of RT enzyme and reaction was allowed to proceed for $2 \mathrm{~h}$ at $52{ }^{\circ} \mathrm{C}$. RT enzyme was inactivated at $70{ }^{\circ} \mathrm{C}$ for $15 \mathrm{~min}$. Reverse transcription reactions were also performed on un-modified RNAs (DMSO only) at the conditions used for modified RNA samples.

RNA was sequenced by RT/chain termination using dideoxynucleotidetriphosphates (ddNTPs) at a ratio of 1:1 ddNTP to dNTP. Ten pmol of ES7 RNA in TE buffer and 40 pmol of primer 
were used for sequencing reactions. A reaction without ddNTPs identified natural polymerase falloff peaks.

Capillary Electrophoresis of RT Reaction Products. Analysis of RT reaction productions was performed as described previously. [32]

SHAPE Data Processing. SHAPE data were processed as described [31]. SHAPE data were mapped onto secondary structures with the program RiboVision [46].

\section{Folding/Unfolding}

Melting curves for ES7 RNA were determined by absorbance at $260 \mathrm{~nm}$ as a function of temperature with a thermostated Varian Cary-1E UV spectrophotometer. RNA was concentrated by Speedvac to at least $1 \mu \mathrm{g} / \mu \mathrm{L}$ and added to melting buffer (180 mM NaCl, $20 \mathrm{mM}$ Tris-Hepes, pH 8.0) to reach an initial absorbance of $0.30-0.33$ at $260 \mathrm{~nm}$. Samples were heated from $15^{\circ} \mathrm{C}$ to $95^{\circ} \mathrm{C}$ at 3 ${ }^{\circ} \mathrm{C} / \mathrm{min}$ in the spectrophotometer to unfold the RNA. Melting transitions were obtained by repeated heating and cooling at $0.5^{\circ} \mathrm{C} / \mathrm{min}$. Due to the RNA size the temperature ramp was less than 1 ${ }^{\circ} \mathrm{C} / \mathrm{min}$, which is commonly used for melting short duplexes [47]. Superimposition of heating and cooling curves was used to confirm equilibrium during melting. Thermodynamic model information as well as information on fitting and parameter estimation are described in the Supplementary Materials.

\section{Pull-down assays and LC-MS/MS analysis}

The DNA anchor was the same sequence as the SHAPE primer, modified with a biotin label on the 5' end (Table S.3). ES7 RNA $(1.3 \mu \mathrm{M})$ was annealed to $2 \mu \mathrm{M}$ of the DNA anchor in the buffer used to melt the RNA and annealed as described for SHAPE experiments. SoftLink ${ }^{\mathrm{TM}}$ Soft Release Avidin Resin (Promega) was washed three times with lysis buffer [0.1\% (w/v) sodium deoxycholate, $100 \mathrm{mM} \mathrm{NaCl}, 1 \mathrm{mM}$ EDTA, $50 \mathrm{mM}$ Tris-Cl pH 8.0 and 1x protease inhibitor cocktail containing $1 \mathrm{mM}$ AEBSF and $1.54 \mathrm{mM}$ Aprotonin] also containing $10 \mathrm{U}$ of RNAse inhibitor, $5 \mathrm{mg} / \mathrm{mL}$ of heparin (Fisher Scientific) and $0.5 \mathrm{mg} / \mathrm{mL}$ of yeast tRNA (Roche) at $4{ }^{\circ} \mathrm{C}$. Then, the RNA-biotin assembly was shaken gently at room temperature with $10 \mu \mathrm{L}$ of equilibrated Avidin resin to attach ES7 to the resin.

Pull-down assays were performed with S. cerevisiae cell lysates. One feature of these experiments that distinguishes them from conventional pull down assays is the high abundance of 
the competing rRNA within the lysate. It seems likely that intrinsic competition from endogenous rRNA might attenuate non-specific binding.

A starter culture of $S$. cerevisiae was grown in yeast extract-peptone-dextrose (YPD) media overnight at $30^{\circ} \mathrm{C}$ and used to inoculate a $50 \mathrm{~mL}$ culture. Cells were harvested at an optical density at $600 \mathrm{~nm}\left(\mathrm{OD}_{600}\right)$ of $\sim 1.0$ by pelleting at $770 \mathrm{xg}, 4^{\circ} \mathrm{C}$ for $15 \mathrm{~min}$. Pellets were stored at $-80^{\circ} \mathrm{C}$ until use. Cells were resuspended in lysis buffer and $0.5 \mathrm{~mm}$ Zirconia/Silica beads (BioSpec) were added. Cell lysis was performed on a Mini BeadBeater 16 (BioSpec) with three 30 sec cycles and interleaved by 2 minutes of incubation on ice. Lysates were separated from beads by centrifugation at $1000 \mathrm{xg}$ for $3 \mathrm{~min}$, vortexed and centrifuged at 15,000 $\mathrm{xg}$ for 10 minutes. The supernatant was collected and used for pull-down experiments.

To assay non-specific protein binding to Avidin or the biotinylated DNA anchor, three parallel experiments were performed, i.e. three samples were incubated with the cell lysate: 1) Avidin-biotin primer-RNA, 2) Avidin only, and 3) Avidin-biotin primer complex. One hundred twenty $\mu \mathrm{L}$ of cell lysate were added to each reaction and incubated for one hour at room temperature with end-over-end rotation. Following incubation, samples were transferred to $30 \mu \mathrm{m}$ polyethylene spin columns and washed three times with $200 \mu \mathrm{L}$ of lysis buffer. Digestion buffer containing $50 \mathrm{mM}$ HEPES pH 7.5, 0.1 M urea and 5\% acetonitrile was added to the samples and digestion was carried out overnight at $31^{\circ} \mathrm{C}$ with Lys-C at a $\sim 1: 200$ Lys-C:protein ratio. Flowthrough digests were collected. Avidin beads on spin columns were washed twice with a solution containing $75 \%$ acetonitrile and $0.5 \%$ acetic acid, and all flow-through was collected and combined for each sample. Acetonitrile was removed by evaporation and the peptides were purified with the stage tip method [48] and dried again. Purified samples were dissolved in 5\% acetonitrile and 1\% formic acid for liquid chromatography tandem mass spectrometry (LC-MS/MS). Further details on LC-MS/MS runs and data analysis are found in the Supplementary Materials.

\section{Electrophoretic Mobility Shift Assays (EMSA)}

\section{Cloning of tRNA-synthetases}

The cDNA for S. cerevisiae aspartyl-tRNA synthetase (AspRS), lysil-tRNA synthetase (LysRS) and tyrosyl-tRNA synthetase (TysRS) was obtained from DNASU plasmid repository [49]. Synthetase DNA was amplified by PCR to add NdeI and XhoI restriction sites at the 5' and 3' ends of the corresponding genes and cloned into pET21b (Novagen) with a C-terminal 6x histidine tag. 
Primer sequences are described in Table S.4. E. coli BL21 (DE3) transformants were selected based on ampicillin resistance ( $50 \mu \mathrm{g} / \mathrm{mL})$ and screened for insert by colony PCR.

tRNA-synthetase Expression and Purification

Three mL starter cultures of E.coli BL21 (DE3) transformed cells were incubated overnight at $37^{\circ} \mathrm{C}$ with $50 \mu \mathrm{g} / \mathrm{mL}$ ampicillin. These cultures were used to inoculate $(1 \% \mathrm{v} / \mathrm{v}) 100 \mathrm{~mL}$ cultures in a shaking incubator at $37^{\circ} \mathrm{C}$ until $\mathrm{OD}_{600}$ reached $0.5-0.7$. Expression was induced by addition of $0.5 \mathrm{mM}$ final concentration of isopropyl $\beta$-D-1-thiogalactopyranoside (IPTG) and cultures were incubated for $4 \mathrm{~h}$ at $37^{\circ} \mathrm{C}$. Cells were harvested by spinning at $4{ }^{\circ} \mathrm{C}$ and $3900 \mathrm{xg}$ for $15 \mathrm{~min}$. Pellets were stored at $-80{ }^{\circ} \mathrm{C}$ until use.

Protein purification was carried out by standard immobilized metal affinity chromatography (IMAC). Cell pellets were resuspended in $5 \mathrm{~mL}$ of $50 \mathrm{mM}$ sodium phosphate, 300 $\mathrm{mM} \mathrm{NaCl}$, and $20 \mathrm{mM}$ imidazole at $\mathrm{pH}$ 8.0. Cell lysis was performed in ice water by sonication with QSonica Q125 at 50\% amplitude for $30 \mathrm{sec}$ nine times with $30 \mathrm{sec}$ intervals followed by centrifugation in a Sorvall RC 5Bplus centrifuge at $4{ }^{\circ} \mathrm{C}, 23,426 \mathrm{xg}$ for $30 \mathrm{~min}$. Clarified cell lysate was bound to $1 \mathrm{~mL}$ of Ni-NTA resin with gentle rocking at $4{ }^{\circ} \mathrm{C}$ for $45 \mathrm{~min}$, and then purified with column chromatography. The resin was washed with two times with five column volumes (CVs) of $50 \mathrm{mM}$ sodium phosphate $\mathrm{pH}$ 8.0, $300 \mathrm{mM} \mathrm{NaCl}$ and $50 \mathrm{mM}$ imidazole. Protein was eluted with 0.5 CVs of $50 \mathrm{mM}$ sodium phosphate $\mathrm{pH} 8.0,300 \mathrm{mM} \mathrm{NaCl}$ and $250 \mathrm{mM}$ imidazole. Protein concentration was measured by BCA [50]. Active fractions were concentrated and stored in 50\% (v/v) glycerol. Protein purity and integrity was analyzed by sodium dodecyl sulfate polyacrylamide gel electrophoresis (SDS-PAGE).

\section{ES7 rRNA/aaRSs Interactions}

RNA-protein interactions were characterized by EMSA as described previously [32] with the following modifications. A $10 \mu \mathrm{M}$ solution of ES7 RNA was prepared in $20 \mathrm{mM}$ Tris-Hepes, pH 8.0 and annealed by cooling from $90^{\circ} \mathrm{C}$ to $25^{\circ} \mathrm{C}$ at $2^{\circ} \mathrm{C} / \mathrm{min}$. aaRSs were introduced at varying concentrations ( $0.25 \mu \mathrm{M}-10 \mu \mathrm{M}$ final) and incubated with $1 \mu \mathrm{M}$ of ES7 RNA (final concentration) for $20 \mathrm{~min}$ at room temperature. Multiprotein EMSA was performed with fixed RNA ( $4 \mu \mathrm{M})$ and fixed protein concentration (10 $\mu \mathrm{M}$ LysRS and $10 \mu \mathrm{M}$ TyrRS) in 20 mM Tris-Hepes, pH 8.0. RNA-protein incubation was also performed for $20 \mathrm{~min}$ at room temperature. RNA-protein interactions were analyzed on 5\% native-PAGE with 3\% glycerol. Gels were visualized using a two-color fluorescent dye protocol in a Typhoon FLA 9500 (GE Healthcare) [51]. In a two-color fluorescent EMSA, un- 
complexed nucleic acid is green, free protein is red and the nucleic acid protein complexes are yellow, although slight leaking between channels of the Typhoon imager was observed. Control reactions used a fragment of Domain III rRNA from T. thermophilus.

\section{ACKNOWLEDGEMENTS}

S. cerevisiae genomic DNA was kindly provided by Dr. Kirill S. Lobachev. The authors thank Dr. Timothy K. Lenz for helpful discussions on SHAPE experiments and analysis, Eric B. O'Neill for helpful discussion on RNA transcription and purification, and Dr. Anton S. Petrov and Dr. Chad Bernier for discussions of ribosomal structure and variability. R.W. acknowledges Georgia Tech and the Blanchard Assistant Professorship. L.M.G.R. acknowledges funding through National Science Foundation Graduate Research Fellowship (Grant No. DGE-1148903) and the Alfred P. Sloan \& GaTech UCEM Minority Doctoral Fellowship.

\section{AUTHOR CONTRIBUTIONS}

L.M.G.R., J.M.S., J.C.B., R.W., R.M.W. and L.D.W. conceived and designed the experiments; L.M.G.R. and J.M.S. performed the experiments; L.M.G.R., J.M.S. and N.A.K. analyzed data; L.M.G.R., J.M.S., N.A.K. and L.D.W. prepared figures; and L.M.G.R., J.M.S., R.W., R.M.W. and L.D.W wrote the paper. 


\section{REFERENCES}

[1] Shoemaker CJ, Green R. Translation drives mRNA quality control. Nat. Struct. Mol. Biol. 2012;19:594601.

[2] Sherman MY, Qian S-B. Less is more: Improving proteostasis by translation slow down. Trends Biochem. Sci. 2013;38:585-91.

[3] Pechmann S, Willmund F, Frydman J. The ribosome as a hub for protein quality control. Mol. Cell. 2013;49:411-21.

[4] Petrov AS, Bernier CR, Hsiao C, Norris AM, Kovacs NA, Waterbury CC, et al. Evolution of the ribosome at atomic resolution. Proc. Natl. Acad. Sci. U.S.A. 2014;111:10251-6.

[5] Ware VC, Tague BW, Clark CG, Gourse RL, Brand RC, Gerbi SA. Sequence analysis of 28S ribosomal DNA from the amphibian xenopus laevis. Nucleic Acids Res. 1983;11:7795-817.

[6] Clark CG, Tague BW, Ware VC, Gerbi SA. Xenopus laevis 28S ribosomal RNA: A secondary structure model and its evolutionary and functional implications. Nucleic Acids Res. 1984;12:6197-220.

[7] Hassouna N, Michot B, Bachellerie JP. The complete nucleotide sequence of mouse 28S rRNA gene. Implications for the process of size increase of the large subunit rRNA in higher eukaryotes. Nucleic Acids Res. 1984;12:3563-83.

[8] Gerbi SA. Expansion segments: Regions of variable size that interrupt the universal core secondary structure of ribosomal RNA. In: Zimmermann RA, Dahlberg AE, editors. Ribosomal RNA-structure, evolution, processing, and function in protein synthesis. Boca Raton, FL: CRC Press; 1996. p. 71-87. [9] Melnikov S, Ben-Shem A, Garreau de Loubresse N, Jenner L, Yusupova G, Yusupov M. One core, two shells: Bacterial and eukaryotic ribosomes. Nat. Struct. Mol. Biol. 2012;19:560-7.

[10] Ben-Shem A, Jenner L, Yusupova G, Yusupov M. Crystal structure of the eukaryotic ribosome. Science. 2010;330:1203-9.

[11] Han H, Schepartz A, Pellegrini M, Dervan PB. Mapping RNA regions in eukaryotic ribosomes that are accessible to methidiumpropyl-EDTA. Cntdot. Fe (II) and EDTA. Cntdot. Fe (II). Biochemistry. 1994;33:9831-44.

[12] Sweeney R, Chen L, Yao M-C. An rRNA variable region has an evolutionarily conserved essential role despite sequence divergence. Mol. Cell. Biol. 1994;14:4203-15.

[13] Jeeninga RE, Van Delft $Y$, de Graaff-Vincent M, Dirks-Mulder A, Venema J, Raué HA. Variable regions v13 and v3 of saccharomyces cerevisiae contain structural features essential for normal biogenesis and stability of $5.8 \mathrm{~s}$ and 25s rRNA. RNA. 1997;3:476.

[14] Ramesh M, Woolford JL. Eukaryote-specific rRNA expansion segments function in ribosome biogenesis. RNA. 2016.

[15] Gao H, Ayub MJ, Levin MJ, Frank J. The structure of the $80 \mathrm{~S}$ ribosome from trypanosoma cruzi reveals unique rRNA components. Proc. Natl. Acad. Sci. U.S.A. 2005;102:10206-11.

[16] Hashem Y, des Georges A, Fu J, Buss SN, Jossinet F, Jobe A, et al. High-resolution cryo-electron microscopy structure of the trypanosoma brucei ribosome. Nature. 2013;494:385-9.

[17] Fleischer TC, Weaver CM, McAfee KJ, Jennings JL, Link AJ. Systematic identification and functional screens of uncharacterized proteins associated with eukaryotic ribosomal complexes. Genes Dev. 2006;20:1294-307.

[18] Beckmann BM, Horos R, Fischer B, Castello A, Eichelbaum K, Alleaume AM, et al. The RNA-binding proteomes from yeast to man harbour conserved enigmrbps. Nat Commun. 2015;6:10127.

[19] Huh W-K, Falvo JV, Gerke LC, Carroll AS, Howson RW, Weissman JS, et al. Global analysis of protein localization in budding yeast. Nature. 2003;425:686-91.

[20] Huang DW, Sherman BT, Lempicki RA. Systematic and integrative analysis of large gene lists using david bioinformatics resources. Nature protocols. 2009;4:44-57. 
[21] Huang DW, Sherman BT, Lempicki RA. Bioinformatics enrichment tools: Paths toward the comprehensive functional analysis of large gene lists. Nucleic Acids Res. 2009;37:1-13.

[22] Köhrer C, Mayer C, Neumair O, Gröbner P, Piendl W. Interaction of ribosomal L1 proteins from mesophilic and thermophilic archaea and bacteria with specific L1-binding sites on 23S rRNA and mRNA. Eur. J. Biochem. 1998;256:97-105.

[23] Uchiumi T, Sato N, Wada A, Hachimori A. Interaction of the sarcin/ricin domain of 23 s ribosomal RNA with proteins L3 and L6. J. Biol. Chem. 1999;274:681-6.

[24] Wilkinson KA, Vasa SM, Deigan KE, Mortimer SA, Giddings MC, Weeks KM. Influence of nucleotide identity on ribose 2'-hydroxyl reactivity in RNA. RNA. 2009;15:1314-21.

[25] Weeks KM, Mauger DM. Exploring RNA structural codes with SHAPE chemistry. Acc. Chem. Res. 2011;44:1280-91.

[26] Zuker M. Mfold web server for nucleic acid folding and hybridization prediction. Nucleic Acids Res. 2003;31:3406-15.

[27] Ben-Shem A, de Loubresse NG, Melnikov S, Jenner L, Yusupova G, Yusupov M. The structure of the eukaryotic ribosome at 3.0 ̊̊ resolution. Science. 2011;334:1524-9.

[28] Leshin JA, Heselpoth R, Belew AT, Dinman J. High throughput structural analysis of yeast ribosomes using hshape. RNA biology. 2011;8:478-87.

[29] Merino EJ, Wilkinson KA, Coughlan JL, Weeks KM. RNA structure analysis at single nucleotide resolution by selective 2'-hydroxyl acylation and primer extension (SHAPE). J. Am. Chem. Soc.

2005;127:4223-31.

[30] Mortimer SA, Weeks KM. Time-resolved RNA SHAPE chemistry. J. Am. Chem. Soc. 2008;130:1617880.

[31] Athavale SS, Gossett JJ, Hsiao C, Bowman JC, O'Neill E, Hershkovitz E, et al. Domain III of the T. thermophilus 23S rRNA folds independently to a near-native state. RNA. 2012;18:752-8.

[32] Hsiao C, Lenz TK, Peters JK, Fang PY, Schneider DM, Anderson EJ, et al. Molecular paleontology: A biochemical model of the ancestral ribosome. Nucleic Acids Res. 2013;41:3373-85.

[33] Draper DE, Bukhman YV, Gluick TC. Thermal methods for the analysis of RNA folding pathways. Current protocols in nucleic acid chemistry. 2008/04/23 ed2001. p. 11.3.1-.3.3.

[34] Forconi M, Herschlag D. Metal ion-based RNA cleavage as a structural probe. Methods Enzymol. 2009;468:91-106.

[35] Ohmayer U, Gil-Hernández Á, Sauert M, Martín-Marcos P, Tamame M, Tschochner H, et al. Studies on the coordination of ribosomal protein assembly events involved in processing and stabilization of yeast early large ribosomal subunit precursors. PloS one. 2015;10:e0143768.

[36] Taylor DJ, Devkota B, Huang AD, Topf M, Narayanan E, Sali A, et al. Comprehensive molecular structure of the eukaryotic ribosome. Structure. 2009;17:1591-604.

[37] Havrylenko S, Mirande M. Aminoacyl-tRNA synthetase complexes in evolution. International journal of molecular sciences. 2015;16:6571-94.

[38] Lee SW, Cho BH, Park SG, Kim S. Aminoacyl-tRNA synthetase complexes: Beyond translation. J. Cell Sci. 2004;117:3725-34.

[39] Hausmann CD, Prætorius-Ibba M, Ibba M. An aminoacyl-tRNA synthetase: Elongation factor complex for substrate channeling in archaeal translation. Nucleic Acids Res. 2007;35:6094-102.

[40] Warner JR. The economics of ribosome biosynthesis in yeast. Trends Biochem. Sci. 1999;24:437-40.

[41] Schimmel PR, Soll D. Aminoacyl-tRNA synthetases: General features and recognition of transfer RNAs. Annu. Rev. Biochem. 1979;48:601-48.

[42] Wilkinson KA, Merino EJ, Weeks KM. Selective 2'-hydroxyl acylation analyzed by primer extension (SHAPE): Quantitative RNA structure analysis at single nucleotide resolution. Nature protocols.

2006;1:1610-6. 
[43] Brion P, Westhof E. Hierarchy and dynamics of RNA folding. Annu. Rev. Biophys. Biomol. Struct. 1997;26:113-37.

[44] Colmenarejo G, Tinoco I. Structure and thermodynamics of metal binding in the $p 5$ helix of a group $i$ intron ribozyme. J. Mol. Biol. 1999;290:119-35.

[45] Bowman JC, Lenz TK, Hud NV, Williams LD. Cations in charge: Magnesium ions in RNA folding and catalysis Curr. Opin. Struct. Biol. 2012;22:262-72.

[46] Bernier C, Petrov AS, Waterbury C, Jett J, Li F, Freil LE, et al. Ribovision: Visualization and analysis of ribosomes. Faraday Discuss. 2014;169:195-207.

[47] Puglisi JD, Tinoco I, Jr. Absorbance melting curves of RNA. Methods Enzymol. 1989;180:304-25. [48] Rappsilber J, Mann M, Ishihama Y. Protocol for micro-purification, enrichment, pre-fractionation and storage of peptides for proteomics using stagetips. Nature protocols. 2007;2:1896-906.

[49] Seiler C, Park J, Fiacco M, Throop A, Steel J, Hunter P, et al. A bologist's resource for plasmids: The dnasu and protein structure initiative: Biology-materials repositories (928.1). The FASEB Journal. 2014;28:928.1.

[50] Smith PK, Krohn RI, Hermanson G, Mallia A, Gartner F, Provenzano M, et al. Measurement of protein using bicinchoninic acid. Anal. Biochem. 1985;150:76-85.

[51] Shcherbakov D, Piendl W. A novel view of gel-shifts: Analysis of RNA-protein complexes using a twocolor fluorescence dye procedure. Electrophoresis. 2007;28:749-55. 


\section{FIGURES}

Figure 1

A)

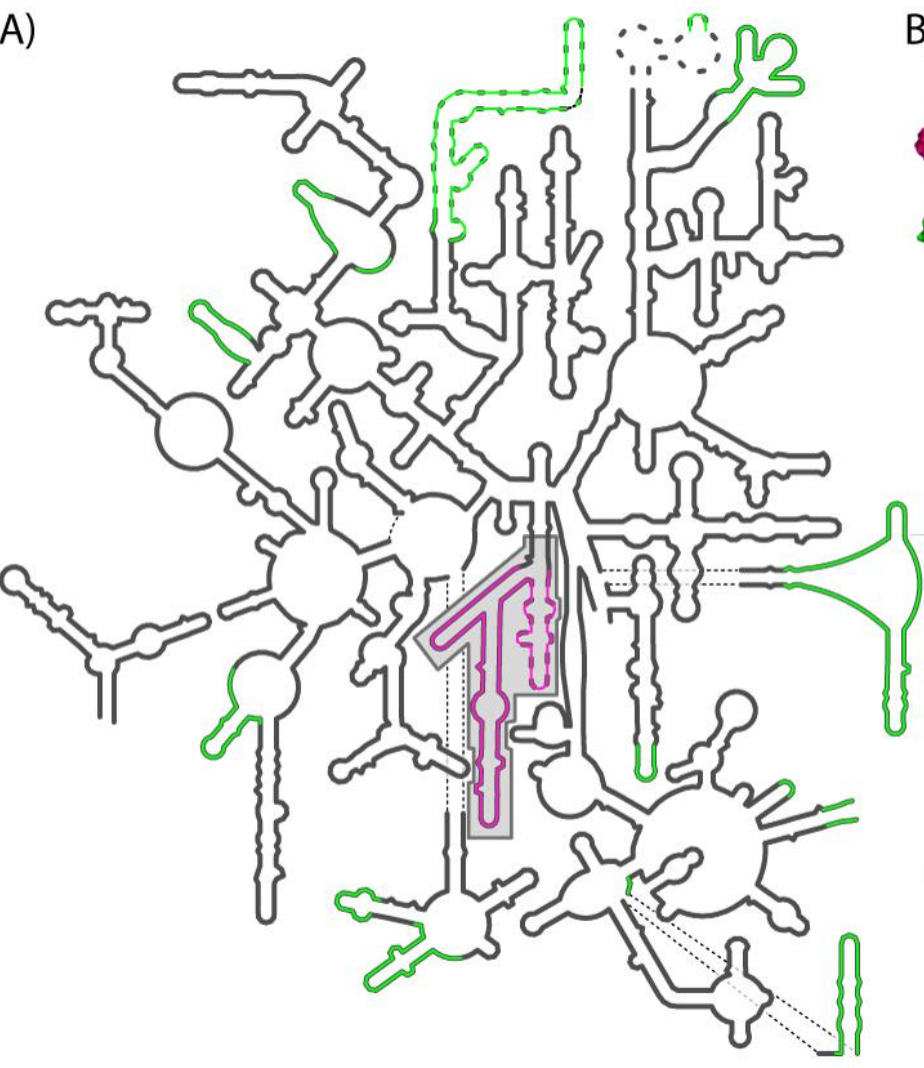

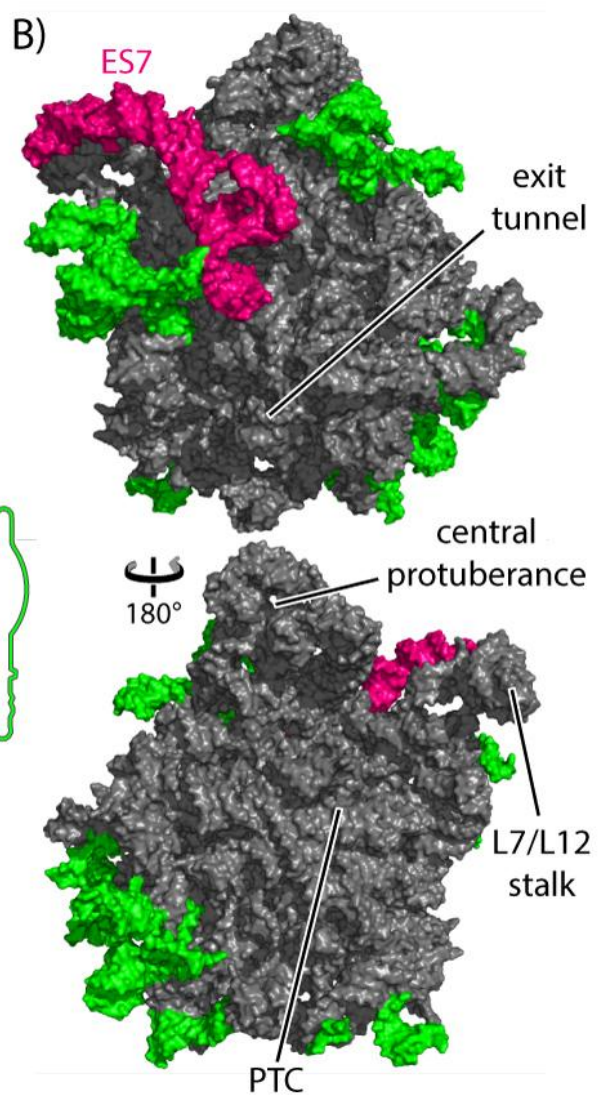


Figure 2

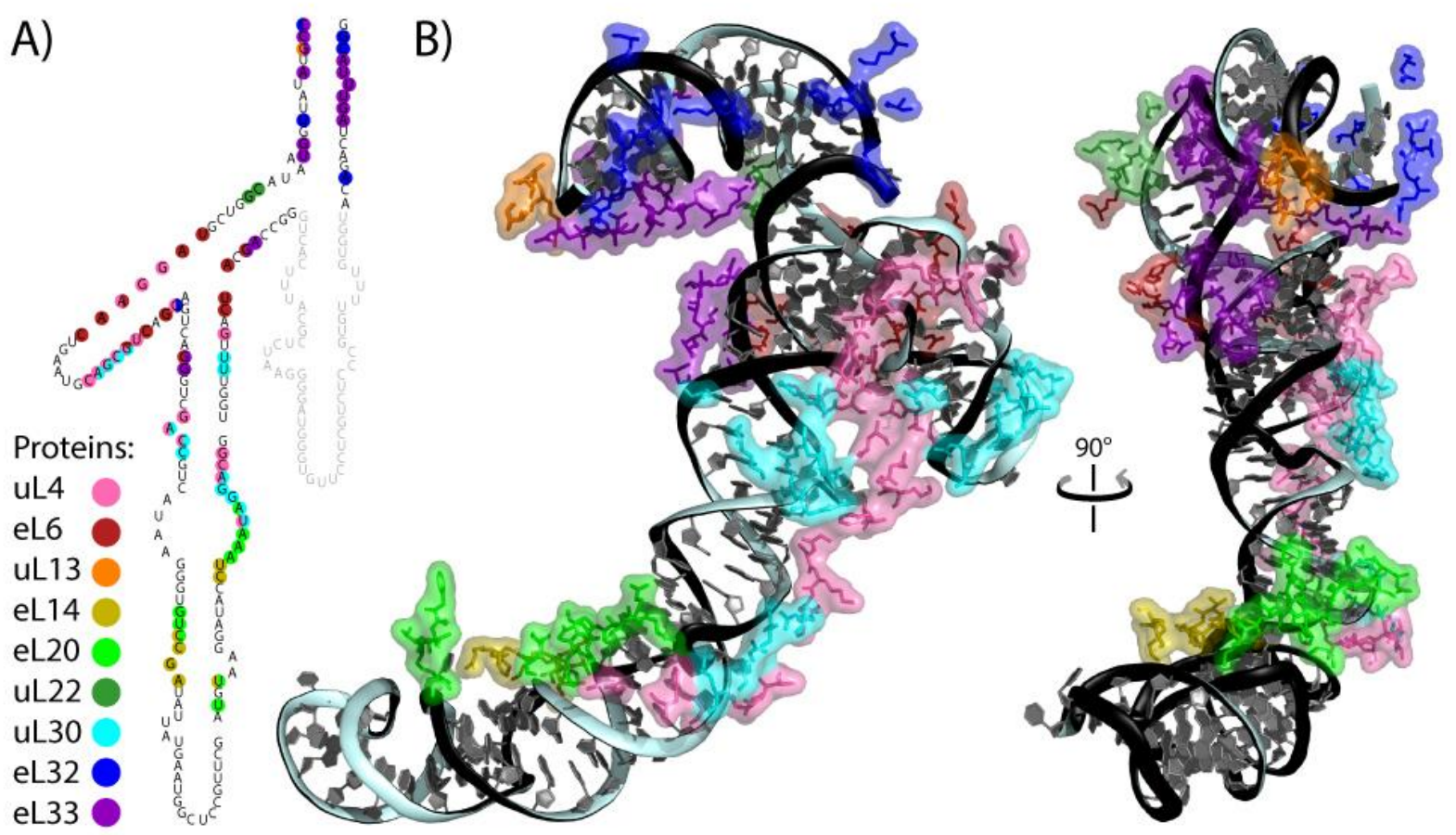


Figure 3

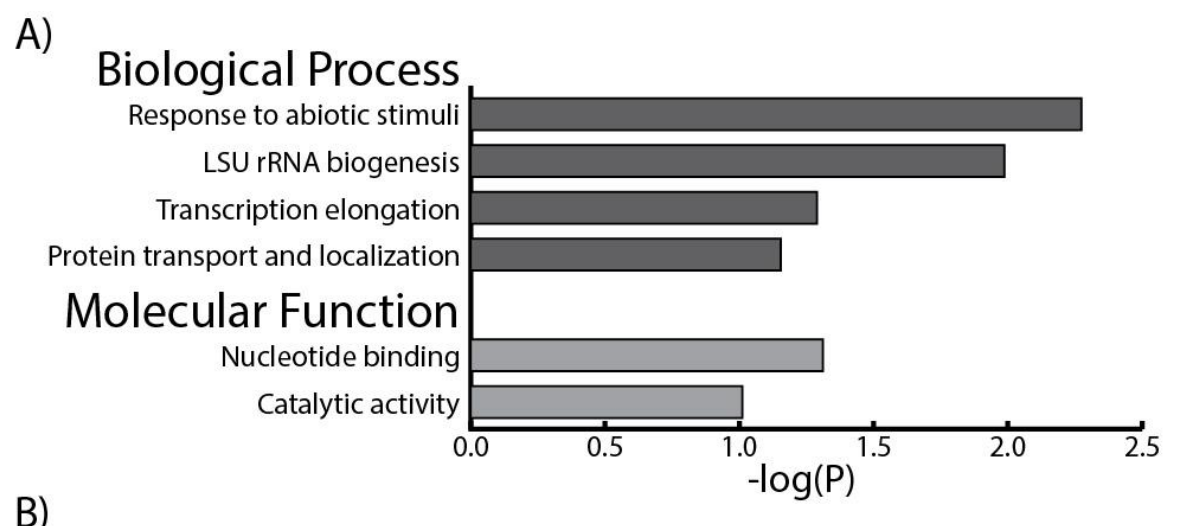

B)

\begin{tabular}{|l|l|}
\hline Biological Process & Genes \\
\hline Response
\end{tabular}

Response to abiotic stimuli SEC1, PBS2, PBI2, SAC6, HXK1, TMA10, BDH1, PNC1

LSU rRNA biogenesis $\quad$ MAK5, RIX7, ERB1, MAK21

$\begin{array}{ll}\text { Transcription elongation } & \text { SPT6, CHD1, CTR9 }\end{array}$

Protein transport and $\quad$ NUM1, SEC1, PBS2, RIX7, YHB1, HXK1, YRB1, RTS1, YGR130C,

localization VMA5, PEP8, SAC6, PBI2, SEC17

Molecular Function Genes

$\begin{array}{ll}\text { Nucleotide binding } & \text { VMA5, MAK5, RIX7, PBS2, CHD1, HXK1, TYS1, DPS1, MET5, ERG1 }\end{array}$

\begin{tabular}{l|l} 
Catalytic activity & MAL32, MAK5, PBS2, RIX7, SPT6, YHB1, HXK1, TYS1, PNC1, DPS1,
\end{tabular} 
Figure 4
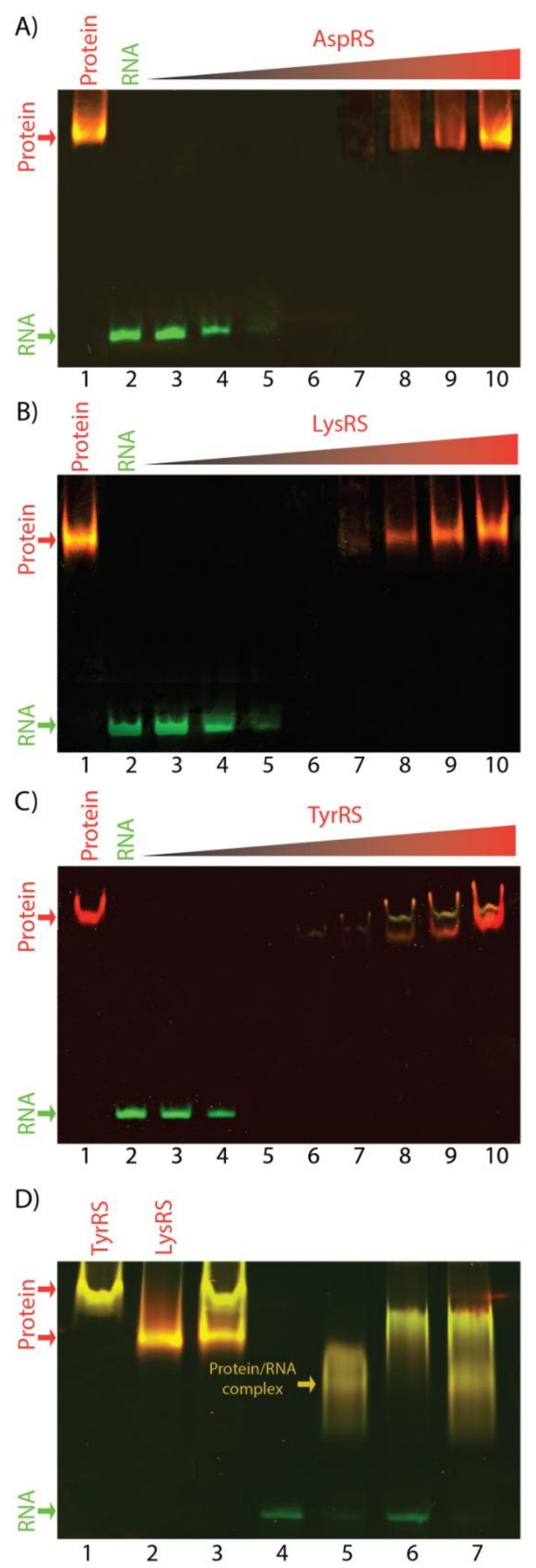
Figure 5

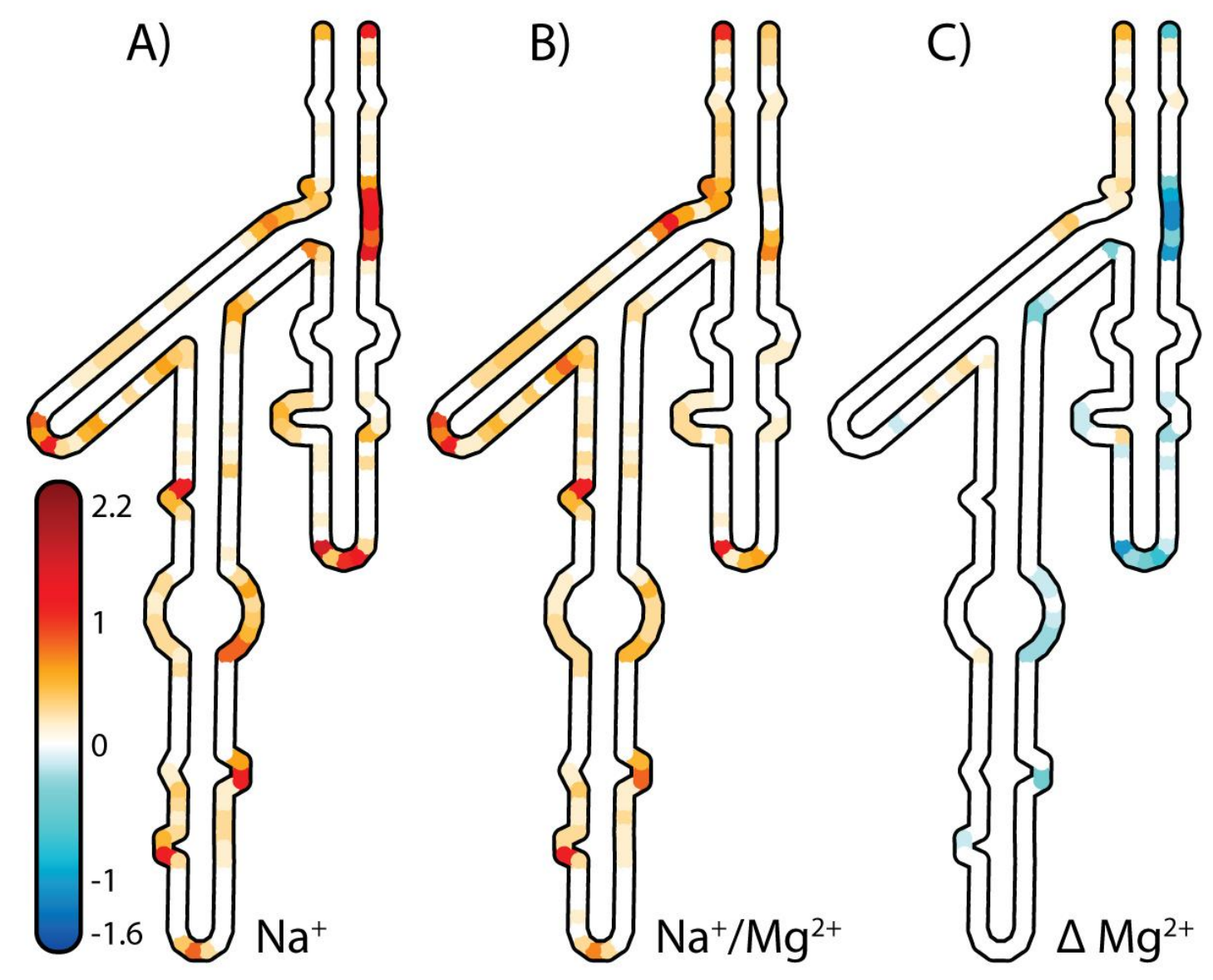


Figure 6

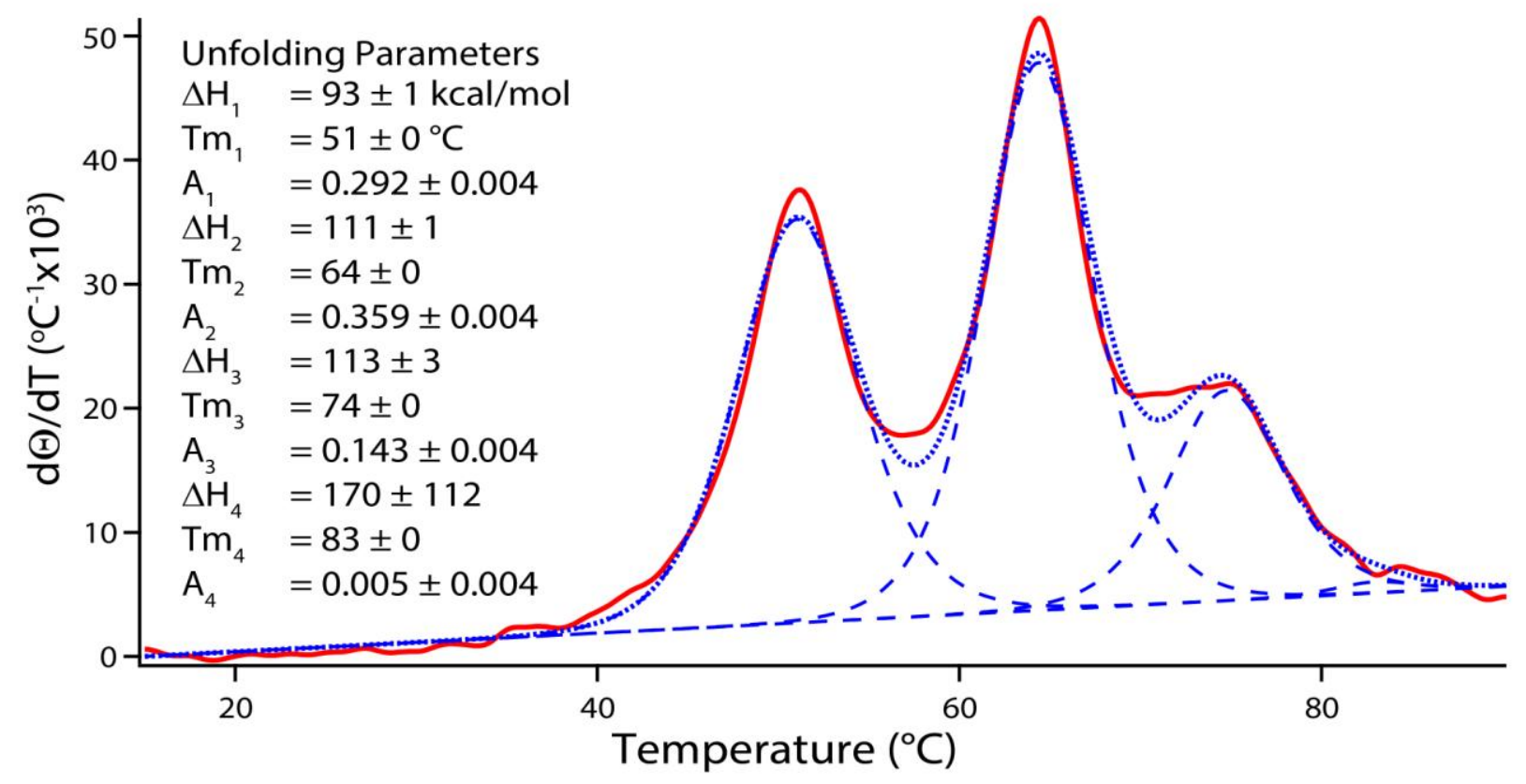




\section{FIGURE LEGENDS}

Figure 1. The LSU rRNA of S. cerevisiae, highlighting expansion segments. A) Secondary structure and B) three dimensional structure of LSU rRNA. Common core rRNA, which is common to all cytoplasmic ribosomes, is dark gray. Expansions of $S$. cerevisiae rRNA from the common core are green, except for expansion segment 7 (ES7) which is pink and is enclosed in a shaded box in panel A. For panel B, the top shows the back view of the LSU, and the bottom shows the front (interfacial) view. Locations of structural hallmarks such as the peptidyl transferase center (PTC), the central protuberance, stalk and tunnel exit are indicated. Thick dashed lines in panel A represent RNA that is not observed in the three dimensional structure [10] and is absent in panel B.

Figure 2. ES7 rRNA interacts with ribosomal proteins in the assembled ribosome. A) Secondary structure and B) three dimensional structure of S. cerevisiae ES7. Interactions of ribosomal proteins with ES7 are mapped on to the A) secondary and B) three dimensional structures. In panel A, nucleotides are colored by the protein with which they interact. Nucleotides not present in the three dimensional structure are shown in gray. In panel B, amino acids interacting with ES7 rRNA are colored by the proteins to which they belong. Coordinates are from PDB entry 4 V88.

Figure 3. Clustering of S. cerevisiae ES7 RNA-proteins identified in this work: based on biological process and molecular function. A) Clusters were organized based on their $P$-values. A greater $\log (P)$ corresponds to higher statistical significance of a particular group of proteins. B) List of genes included in each cluster.

Figure 4. EMSA of S. cerevisiae ES7 RNA with aaRSs. Binding of ES7 to A) AspRS, B) LysRS, C) TyrRS and D) LysRS and TyrRS is shown in vitro. RNA, protein and RNA-protein complexes were visualized by two color EMSA in a native gel. Binding reactions for panels A-C were performed with $1 \mu \mathrm{M}$ RNA and various concentrations of protein. Lane 1 contains $10 \mu \mathrm{M}$ of protein and no RNA. Lane 2 consists of $1 \mu \mathrm{M}$ RNA only. Lanes 3-10 contain $1 \mu \mathrm{M}$ RNA and increasing protein concentration: lane $3-0.25 \mu \mathrm{M}$ protein, lane $4-0.50 \mu \mathrm{M}$, lane $5-1 \mu \mathrm{M}$, lane $6-2 \mu \mathrm{M}$, lane $7-4$ $\mu \mathrm{M}$, lane $8-6 \mu \mathrm{M}$, lane $9-8 \mu \mathrm{M}$ and lane $10-10 \mu \mathrm{M}$. Binding reactions for panel D were performed with $4 \mu \mathrm{M}$ RNA and $10 \mu \mathrm{M}$ of each protein. Lane 1 contains $10 \mu \mathrm{M}$ of TyrRS, Lane 2 contains $10 \mu \mathrm{M}$ of LysRS and Lane 3 contains $10 \mu \mathrm{M}$ of TyrRS and $10 \mu \mathrm{M}$ of LysRS, as controls. Lanes $4-7$ contain 4 $\mu \mathrm{M}$ RNA and various aaRSs: lane 4 - no protein, lane 5 - $10 \mu \mathrm{M}$ TyrRS, lane 6 - $10 \mu \mathrm{M}$ LysRS and lane 7 - $10 \mu \mathrm{M}$ TyrRS and $10 \mu \mathrm{M}$ LysRS. 
Figure 5. SHAPE reactivities in $\mathrm{Na}^{+}$only and in $\mathrm{Na}^{+} / \mathrm{Mg}^{2+}$ reveal $\mathrm{Mg}^{2+}$-dependent structural changes of $S$. cerevisiae ES7 rRNA. SHAPE reactivities are mapped onto S. cerevisiae ES7 rRNA secondary structure. Shape reactivities were determined in presence of A) $\mathrm{Na}^{+}$or B) $\mathrm{Na}^{+}$and $\mathrm{Mg}^{2+}$. Orange or red nucleotides show moderate to high SHAPE reactivity. Ivory or white nucleotides show low or no SHAPE reactivity. C) $\mathrm{Mg}^{2+}$ induces changes in SHAPE reactivity. Nucleotides in red show increased reactivity in the presence of $\mathrm{Mg}^{2+}$. Nucleotides in blue show decreased reactivity. These figures were generated with RiboVision. All samples contained $200 \mathrm{mM} \mathrm{NaOAc}, 50 \mathrm{mM}$ NaHEPES at pH 8.

Figure 6. Melting profile of $S$. cerevisiae ES7 rRNA. The derivative of fraction unfolded at $260 \mathrm{~nm}$ with respect to temperature was computed. The derivative was fit to a non-sequential, independent transition model with Igor v.6.37. The enthalpy $\left(\Delta \mathrm{H}_{\mathrm{n}}\right)$, melting temperature $\left(\mathrm{T}_{\mathrm{m}, \mathrm{n}}\right)$ and the relative hyperchromicity $\left(A_{n}\right)$ were estimated for each transition, $n$. The observed derivative is red, the fit is dotted blue and the deconvolution of the fit is dashed blue. 


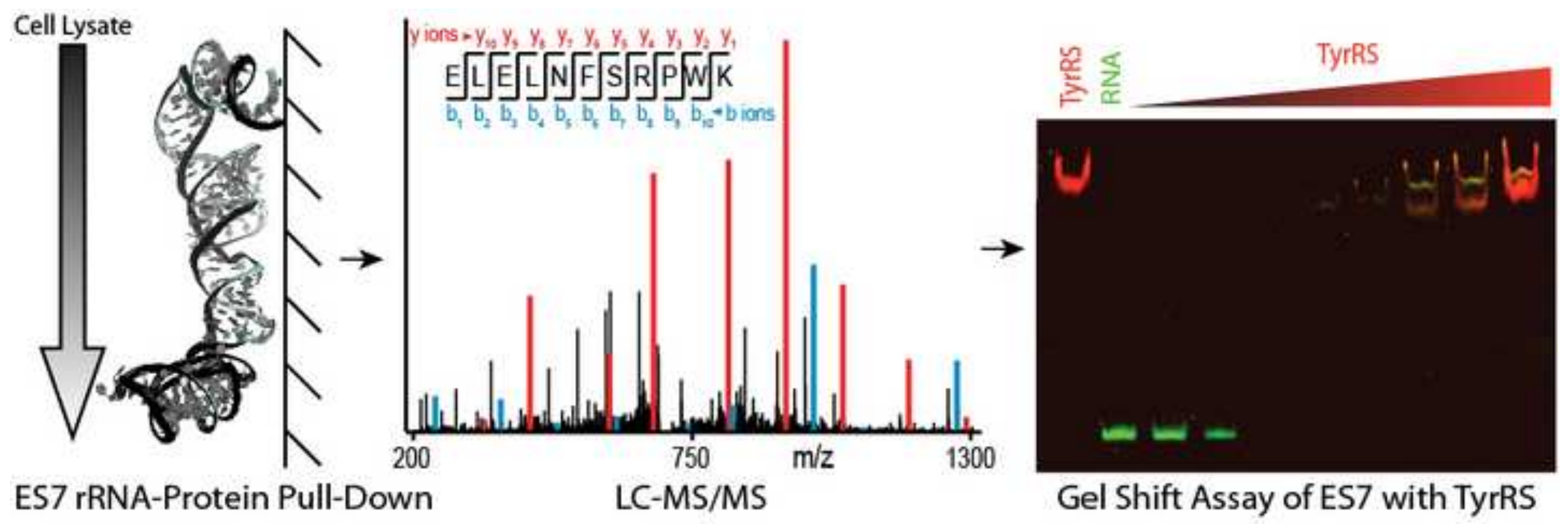

